\title{
Comparative economic analysis of fish cum pig and fish cum dairy integrated farming systems
}

\author{
Jharna Choudhury*, Dipanjan Kashyap ${ }^{1}$, P. L. Kikon ${ }^{1}$, Rajkumari R. Devi ${ }^{1}$ and H. Aisolia Devi ${ }^{1}$ \\ Department of Agricultural Economics (MBA- Agri Business), Assam Agricultural University \\ Jorhat (Assam) India \\ (E-mail : jchoudhury671@gmail.com)
}

\begin{abstract}
Integrated fish farming is a system of producing fish in combination with other agricultural/livestock farming operations centered around the fish pond. The study was conducted in Kalong-Kapili NGO of Kamrup (Metro) district of Assam with the objectives of evaluating the cost and return aspects of fish cum pig and fish cum dairy farming systems and identifying the more profitable integration model which gives optimum utilization of given resources. A total of 44 farmers comprising of 24 fish cum pig farmers and 20 fish cum dairy farmers were randomly selected for data collection. Based on data collected, economic analysis of the integrated farming systems were done by using various cost and return concepts. Total operational cost (Cost C) in fish cum pig farming (Rs. 554832.18) was found lower than fish cum dairy farming (Rs. 632267.66). Net income (Rs. 787609.42) and benefitcost ratio (2.42) were found higher in fish-pig integration, which clearly states that integrated fish cum pig farming is more profitable than integrated fish cum dairy farming.
\end{abstract}

Key Words : Integrated farming, Fish, Costs, Net return, BC Ratio

View Point Article : Choudhury, Jharna, Kashyap, Dipanjan, Kikon, P.L., Devi, Rajkumari R. and Devi, H. Aisolia (2021). Comparative economic analysis of fish cum pig and fish cum dairy integrated farming systems. Internat. J. agric. Sci., 17 (2) : 204-208, DOI:10.15740/ HAS/IJAS/17.2/204-208. Copyright@2021: Hind Agri-Horticultural Society.

Article History : Received : 22.02.2021; Revised : 25.02.2021; Accepted : 14.03.2021

\footnotetext{
* Author for correspondence :

${ }^{1}$ Krishi Vigyan Kendra (AAU), Darrang (Assam) India
} 